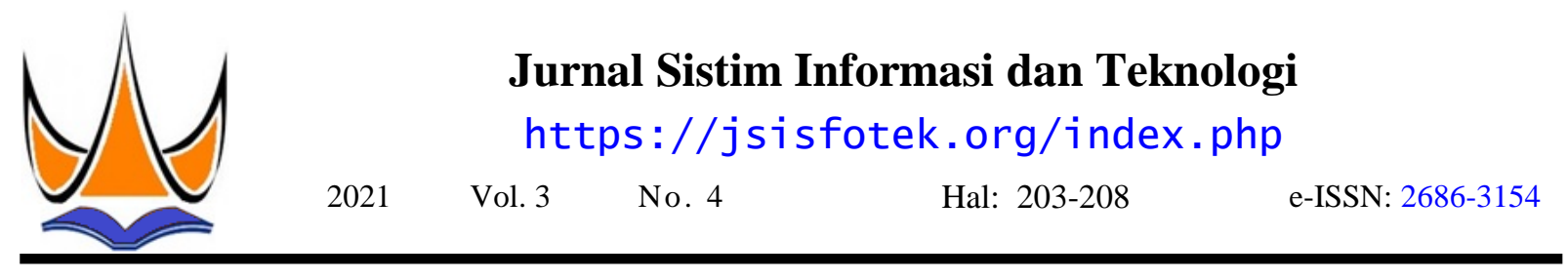

\title{
Sistem Pakar dalam Menganalisis Defisiensi Nutrisi Tanaman Hidroponik Menggunakan Metode Certainty Factor
}

\author{
Yerri Kurnia Febrina ${ }^{1 凶}$, Sarjon Defit ${ }^{2}$, Gunadi Widi Nurcahyo ${ }^{3}$ \\ ${ }^{1}$ Independent Researcher \\ ${ }^{2,3}$ Universitas Putra Indonesia YPTK Padang \\ inutfebrina@gmai1.com
}

\begin{abstract}
Currently the Expert system has become a field of research for computer scientists as well as agricultural scientists for applications in various information development. The Expert System can be designed to simulate one or more of the ways an agricultural expert uses his knowledge and experience in making the diagnosis and passing on the necessary recommendations regarding nutritional deficiencies. Nutrient deficiency is a lack of food for survival in plants. The nutrient content of plant parts, especially the leaves, is very relevant to be used to identify nutritional deficiencies. Provide the results of a diagnosis of nutritional deficiency to farmers to be a benchmark for improving plant nutrients and providing good nutrition for hydroponic plants. The data used are nutritional deficiency data and symptoms as well as nutritional solutions obtained from farmer data at the Payakumbuh City Agriculture Office. The method used in this expert system is the Certainty Factor (CF) method. This method provides a diagnosis in the form of certainty or uncertainty of conditions in the rules used to conclude. The results of testing this method showed as many as 12 nutritional deficiencies were detected with 41 symptoms experienced. So that it can measure the level of nutritional deficiency that occurs. Expert System in Analyzing Hydroponic Plant Nutrient Deficiency Using Certainty Factor Method can show that predictions are almost 94\% accurate.
\end{abstract}

Keywords: Expert System, Nutritional, Deficiency, Hydroponics, Certainty Factor.

\begin{abstract}
Abstrak
Saat ini sistem Pakar telah menjadi bidang penelitian bagi ilmuwan komputer juga ilmuwan pertanian untuk aplikasi dalam berbagai pengembangan informasi. Sistem Pakar dapat dirancang untuk mensimulasikan satu atau lebih dari cara seorang ahli pertanian menggunakan pengetahuan dan pengalamannya dalam membuat diagnosis dan meneruskan rekomendasi yang diperlukan terkait defisiensi nutrisi. Defesiensi nutrisi adalah kekurangan bahan makanan untuk kelangsungan hidup pada tanaman. Kandungan hara pada bagian tanaman, terutama didaun, sangat relevan digunakan untuk mengidentifikasi defisiensi nutrisi. Memberikan hasil diagnosis defisiensi nutrisi kepada petani untuk dapat menjadi patokan perbaikan hara tanaman serta pemberian nutrisi yang baik untuk tanaman hidroponik. Data yang digunakan adalah data defisiensi nutrisi dan gejala serta solusi pemberian nutrisi yang diperoleh dari data petani pada Dinas Pertanian Kota Payakumbuh. Metode yang dipakai dalam system pakar ini adalah metode Certainty Factor (CF). Metode ini memberikan diagnosis berupa kepastian atau ketidakpastian kondisi dalam rule yang digunakan untuk menyimpulkan. Hasil dari pengujian terhadap metode ini menunjukan sebanyak 12 defisiensi nutrisi yang terdeteksi dengan 41 gejala yang dialami. Sehingga dapat mengukur tingkat defisiensi nutrisi yang terjadi. Sistem Pakar dalam Menganalisis Defisiensi Nutrisi Tanaman Hidroponik Menggunakan Metode Certainty Factor dapat menunjukkan bahwa prediksi hamper 94\% akurat.
\end{abstract}

Kata kunci: Sistem Pakar, Defisiensi, Nutrisi, Hidoponik, Certainty Factor.

(C) 2021 JSisfotek

\section{Pendahuluan}

Artificial Intelligence (AI) merupakan teknologi yang meniru perilaku terkait dengan kecerdasan manusia, Penelitian terdahulu Sistem Pakar dimanfaatkan dalam seperti belajar dan pemecahan masalah [1]. Sistem hal diagnosa penyakit tanaman Kakao. Kakao adalah pakar merupakan salah satu cabang AI yang salah satu komoditas ekspor non migas produk utama memanfaatkan pengetahuan khusus untuk biji kakao diolah menjadi berbagai produk khususnya menyelesaikannya masalah tingkat manusia yang ahli minuman makanan, limbah kakao juga dapat [2]. Sebuah kombinasi Sistem Pakar dan metode dimanfaatkan sebagai pupuk organik. Penelitian yang Certainty Factor dipelajari dan diterapkan pada dilakukan menyatakan bahwa penerapan metode diagnosa defesiensi nutrisi tanaman hidroponik ini. Certainty Factor untuk mendiagnosa penyakit tanaman Certainty Factor (CF) termasuk dalam fungsi Kakao dengan perhitungan akurasi di mana hasilnya probabilitas, yang pertama kali diusulkan pada tahun didapatkan tingkat akurasi sebesar 85,7\% [5].

1990 [3]. Metode ini memungkinkan kesimpulan atau diagnosis, meskipun ada ketidakpastian kondisi atau
Penelitian terdahulu Sistem Pakar metode Certainty Factor juga digunakan dalam Diagnosa Penyakit Tanaman Bawang Merah. Bawang merah merupakan 
salah satu komoditas sayuran yang potensial untuk dikembangkan di Indonesia. Bawang merah termasuk sayuran yang multiguna yang dimanfaatkan sebagai rempah-rempah pelengkap bumbu masak, bahan untuk industri makanan dan dipakai sebagai obat tradisional. Penelitian ini menggunakan sebanyak 35 data sebagai pengujianya dan dari data tersebut diperoleh nilai akurasi sebesar 85,71\% [6].

Budidaya tanaman saat ini sudah berkembang sangat pesat, Hidroponik merupakan alternatif yang lebih baik dan dapat diartikan sebagai budidaya tanaman tanpa tanah. Pada tanaman hidroponik kapasitas penyangga hara dari sistem dan kemampuan untuk membuat perubahan perlu diperhatikan dua aspek gizi yaitu penyediaan unsur hara dari unsur hara sistem pengiriman dan respon hara tanaman [7]. Agar tetap kompetitif, para petani maju tergantung pada spesialis pertanian dan panduan yang akan diberikan informasi untuk pengambilan keputusan. Sayangnya, bantuan spesialis pertanian umumnya tidak dapat diakses ketika petani membutuhkannya. Berdasarkan masalah ini, Sistem Pakar diakui sebagai alat yang luar biasa dengan luas potensi dalam produksi pertanian [8]. Menggunakan sumber daya teknologi seperti tenaga ahli sistem untuk mengidentifikasi kekurangan unsur hara secara dini dapat dikenali supaya memudahkan publik untuk menghemat waktu, sumber daya, dan memudahkan pengguna untuk mendeteksi defisiensi nutrisi tanaman [9]. Sistem Pakar yang dirancang dapat mensimulasikan satu atau lebih dari cara seorang ahli pertanian menggunakan pengetahuan dan pengalamannya dalam membuat diagnosis dan meneruskan rekomendasi yang diperlukan terkait defisiensi nutrisi. Defesiensi nutrisi merupakan kekurangan bahan makanan untuk kelangsungan hidup pada tanaman. Kandungan hara pada bagian tanaman, terutama di daun, sangat relevan digunakan untuk mengidentifikasi defisiensi nutrisi [10].

\section{Metodologi Penelitian}

Metodologi penelitian yang digunakan dalam penelitian ini terdiri dari beberapa langkah-langkah dan kerangka dari penelitian ini dapat dilihat pada Gambar 1. Kerangka kerja merupakan penggambaran terperinci yang didasari dengan cara yang terorganisir sehingga penelitian dapat mencapai tujuannya dan memiliki penilaian yang semestinya. Setiap tahapan kerangka kerja dijelaskan pada sub bagian-sub bagian penelitian ini.

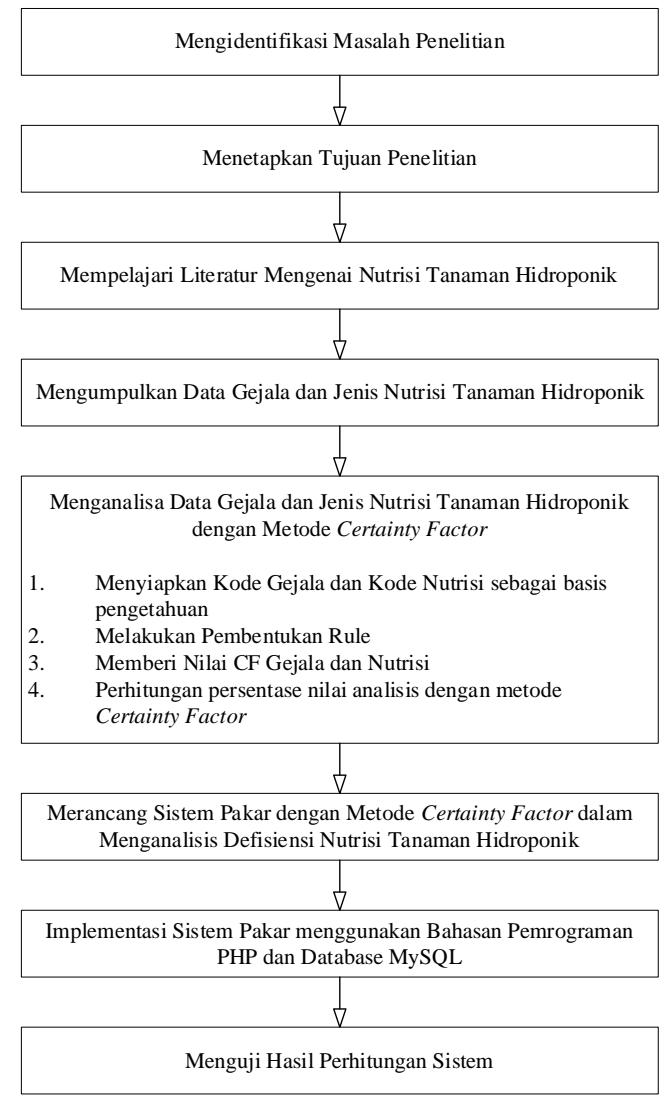

Gambar 1. Kerangka Kerja Penelitian

\subsection{Identifikasi Masalah}

Indentifikasi masalah adalah tahapan untuk menemukan masalah sebelum melakukan penelitian. Identifikasi masalah diselesaikan dengan bergerak menuju objek pemeriksaan. Alasan melakukan tahapan ini adalah untuk menentukan permasalahan yang terjadi dengan baik, sehingga diyakini bahwa penelitian dapat memberikan jawaban yang paling ideal untuk mengatasi permasalahan tersebut. MAsalah yang diidentifikasi pada penelitian ini adalah bagaimana menganalisis defisiensi nutrisi tanaman hidroponik secara tepat dan cepat.

\subsection{Menentukan Tujuan}

Tahapan penentuan tujuan ini merupakan tahapan di mana peneliti mengemukakan tujuan dari penelitian agar tidak keluar dari hasil yang ingin diperoleh. Tujuan penelitian ini adalah untuk menganalisis defisiensi nutrisi tanaman hidroponik.

\subsection{Mempelajari Literatur}

Mempelajari literatur merupakan fase dalam mencari tahu tentang penggunaan sistem pakar dan pemanfaatan metode Certainty Factor. Sebagai metode yang digunakan dalam penelitian, akan digunakan untuk menganalisis nutrisi dan mempelajari spekulasi tentang jenis dan gejala defisiensi nutrisi tanaman hidroponik dan untuk mendapatkan konsekuensi dari jenis nutrisi 
yang dialami dan untuk memberikan penanganan yang tepat atas hasil analisis dari defisiensi nutrisi tersebut.

\subsection{Mengumpulkan Data}

Tahapan pengumpulan data ini dilakukan untuk memperoleh data yang diperlukan dalam penelitian yang dilakukan. Penulis memperoleh data dari pakar 6 pertanian. Data pendukung dalam penelitian ini didapat 7 dari jurnal, buku dan referensi lainnya. Dalam 8 mengumpulkan data penelitian ini juga dilakukan 9 wawancara dengan pakar pertanian pada objek 1 penelitian, yakni Dinas Pertanian Kota Payakumbuh.

\subsection{Analisa Data dengan Metode Certainty Factor}

Tahapan-tahapannya adalah sebagai berikut:

a. Menyiapkan Kode Gejala dan Kode Nutrisi sebagai basis pengetahuan.

b. Melakukan pembentukan rule.

c. Memberi Nilai CF Gejala dan Nutrisi.

d. Perhitungan persentase nilai analisis dengan metode Certainty Factor

\subsection{Perancangan Sistem}

Tahapan perancangan sistem dilakukan dengan mengukur konfigurasi kerangka kerja yang tersusun atas struktur informasi atau data, aplikasi, pengaturan masukkan, dan desain hasil atau keluaran. Perancangan yang digunakan untuk merancang system ini menggunakan UML (Unified Modelling Language), yang merupakan metode permodelan berorientasi objek.

\subsection{Implementasi Sistem}

Penimplementasian sistem pakar menggunakan metode Certainty Factor diterapkan dengan memanfaatkan bahasa pemrograman PHP dan Database MySQL.

\subsection{Pengujian Hasil}

Tahap ini merupakan tahap akhir di mana peneliti melakukan simulasi setelah mendapatkan data dan untuk melihat apakah pembuatan Sistem Pakar telah sesaui dengan tujuan dari peneltian

\section{Hasil dan Pembahasan}

Pada hasil dan pembahasan terdapat beberapa kegiatankegiatan yang akan dilakukan diantaranya sebagai berikut:

\subsection{Analisa Data}

Data yang dimanfaatkan dalam penelitian ini adalah data defisiensi nutrisi yaitu informasi tentang jenis nutrisi, gejala untuk defisiensi nutrisi tanaman hidroponik. Berikut daftar jenis defisiensi nutrisi tanaman hidroponik yang dapat dilihat pada Tabel 1 .
Tabel 1. Tabel Jenis Defisiensi Nutrisi

\begin{tabular}{lll}
\hline No & Kode & Jenis Defisiensi \\
\hline 1 & D01 & Nitrogen (N) \\
2 & D02 & Fosfor (P) \\
3 & D03 & Kalium (K) \\
4 & D04 & Kalsium (Ca) \\
5 & D05 & Magnesium $(\mathrm{Mg})$ \\
6 & D06 & Belerang atau Sulfur (S) \\
7 & D07 & Zat Besi (Fe) \\
8 & D08 & Mangan (Mn) \\
9 & D09 & Tembaga (Cu) \\
10 & D10 & Binc/Seng (Zn) \\
11 & D11 & Molibdenum (Mo) \\
12 & D12 & \\
\hline
\end{tabular}

Berdasarkan dari hasil data yang telah didapatkan dari pakar pertanian ditemukan sebanyak 41 gejala. Setiap gejala diberi identitas dalam pengolahan yaitu dengan simbol $\mathrm{G}$ dan diikuti oleh urutan angka. Simbol dari geja tersebut adalah:

G01: Pertumbuhan tanaman berjalan lambat.

G02: Bila sempat berbuah, buahnya akan kerdil, cepat masak lalu rontok.

G03: Daun hijau kekuningan, pendek, kecil dan tegak.

G04: Daun yang sudah tua berwarna hijau muda, kemudian berubah kuning dan layu.

G05: Bila sempat berbuah, buahnya akan kerdil, cepat masak lalu rontok.

G06: Seluruh warna daun berubah menjadi lebih tua dan sering tampak mengkilap kemerahan.

G07: Tepi daun, cabang dan batang akan berwarna merah keunguan yang lambat laun akan berubah menjadi kuning dan kemudian layu.

G08: Jika tanaman berbuah, buahnya akan kecil, mutunya jelek, dan cepat masak.

G09: Daun tua akan mengkerut dan keriting.

G10: Pada daun akan timbul bercak merah kecoklatan, lalu daun akan mengering dan mati.

G11: Buah tumbuh tidak sempurna, kecil, mutunya jelek, hasilnya sedikit dan tidak tahan simpan.

G12: Tepi daun muda akan berubah menjadi kuning karena chlorosis, yang kemudian menjalar ke tulang daun.

G13: Kuncup muda akan mati karena perakaran kurang sempurna. Jika ada daun yang tumbuh, warnanya akan berubaah dan baberapa jaringan pada daun akan mati.

G14: Daun tua mengalami kerusakan dan gagal membentuk klorofil sehingga tampak bercak cokelat, daun yang semula hijau akan berubah kuning dan pucat.

G15: Daun mengering dan seringkali langsung mati. 
G16: Daya tumbuh biji menjadi berkurang. Bila biji G40: Daun muda berwarna pucat, pinggir daun coklat tumbuh, kualitas akan kurang baik. seperti terbakar, pertumbuhan daun terhambat.

G17: Warna daun muda berubah menjadi hijau muda, G41: Daun tua klorosis dari daun tua terus ke daun tidak merata, sedikit mengkilap agak keputihan, kemudian berubah menjadi kuning kehijauan. muda.

\subsection{Analisa Sistem}

G18: Warna menjadi kekuningan, terutama pada daun muda.

Pada tahap penelitian analisa sistem ini, diperlukan informasi dan data dari beberapa sumber, terutama dari

G19: Pertumbuhan tanaman seolah berhenti, sehingga dun berguguran dan akhirnya tanaman mati.

G20: Khlorosisi pada daun muda diantara vena.

G21: Daun kering, tulang daun hijau pucat - dengan Tabel 2. kecoklatan.

Tabel 2.Tabel Nilai Certainty Factor

G22: Daun berwarna merah kekuningan.

G23: Jaringan daun di beberapa tempat akan mati.

G24: Khlorosis antar tulang daun, bercak 0,4 kecoklatan/abu dan nekrosis dengan tulang daun masih hijau. membahas rule dan pembahasan metode Certainty Factor. Nilai CF (Rule) didapat dari interpretasi "term" dari pakar, yang diubah menjadi nilai CF tertentu sesuai

\begin{tabular}{ll}
\hline Uncertainty Term & Nilai CF \\
\hline 0 & Tidak Yakin \\
0,2 & Hampir Mungkin \\
0,4 & Mungkin \\
0,6 & Kemungkinan Besar \\
0,8 & Hampir Pasti \\
1 & Pasti Ya \\
\hline
\end{tabular}

G25: Ujung daun tidak merata, layu dan mengalami kerusakan dan layu.

Rule adalah teknik mengelola pengetahuan memiliki rumus rule IF E Then $\mathrm{H}$. Evidence (fakta) dan hipotesa yang dihasilkan. Berdasarkan data yang ada maka

G26: Pertumbuhan tanaman menjadi terhambat, dibentuk rule yang disajikan pada Tabel 3. terutama pada jenis tanaman sayur.

G27: Pada daun muda dg pinggir dan tulang daun hijau pucat.

G28: mati mulai dari pucuk batang.

G29: Daun muda kuning.

G30: Daun menjadi kekuningan dan kemerahan, terutama pada daun tua.

G31: Daun berlubang, mengering dan mati.

G32: Tanaman kerdil, ruas-ruas batang memendek, daun mengecil dan mengumpul (resetting) dan 12 klorosis pada daun-daun muda dan intermedier serta adanya nekrosis.

Tabel 3. Tabel Rule

\begin{tabular}{ll}
\hline Rule ke & Rule \\
\hline 1 & IF G01 OR G02 OR G03 OR G04 OR G05 THEN D01 \\
2 & IF G06 OR G07 OR G08 THEN D02 \\
3 & IF G09 OR G10 OR G11 THEN D03 \\
4 & IF G12 OR G13 THEN P04 D04 \\
5 & IF G14 OR G15 OR G16 THEN D05 \\
6 & IF G01 OR G02 OR G17 THEN D06 \\
7 & IF G18 OR G19 OR G20 OR G21 THEN D07 \\
8 & IF G22 OR G23 OR G24 THEN D08 \\
9 & IF G25 OR G26 OR G27 OR G28 OR G29 THEN D09 \\
10 & IF G30 OR G31 OR G32 OR G33 THEN D10 \\
11 & IF G34 OR G35 OR G36 OR G37 OR G38 OR G39 \\
12 & THEN D11 \\
\hline
\end{tabular}

\subsection{Perhitungan Certainty Factor}

G33: Daun keriting dan mengelompok pada bagian Dalam proses pengolahan dengan metode Certainty atas tanaman.

G34: Gejala klorosis dari tepi daun, daun menjadi layu, kering dan mati.

Factor digunakan rumus seperti pada persamaan

CFrule MB-MD

CFcombinasi $\quad$ CFrule + CFrule(1-CFrule)

CFcombinasi * 100

Contoh Kasus 1: Tanaman Bapak Guci Harianto

G36: Gagal pertumbuhan pucuk, batang kaku, pertumbuhan cabang lateral .

Gejala:

G37: Daun berwarna ungu, coklat dan kuning, a. Warna menjadi kekuningan, terutama pada daun menebal, keriting, buah mudah rontok.

G38: Buah dan akar berubah warna, berkarat coklat b. Pertumbuhan tanaman seolah berhenti, sehingga dan pecah. dun berguguran dan akhirnya tanaman mati (G19)

G39: Tanaman buah dan sayur mudah busuk, buah c. Khlorosisi pada daun muda diantara vena (G20) kasar, matang tidak merata, buah keropos

Rule:

IF G18 OR G19 OR G20 OR G21 THEN D07

Jurnal Sistem Informasi dan Teknologi Vol. 3 No. 4 (2021) 203-208 
Defisiensi Nutrisi D07=Defisiensi Nutrisi Zat Besi (Fe)

G18(Pasti Ya[1])(MB[0.8])(MD[0.4]

G19(Hampir Pasti[0.8])(MB[0.6](MD[0.2]

G20(Pasti Ya[1])(MB[1.0])(MD[0.2]

$$
\begin{array}{ll}
\text { CF-G18 } & =(0.8-0.4) * 1=0.4 \\
\text { CF-G19 } & =(0.6-0.2) * 0.8=0.32 \\
\text { CF-G20 } & =(1.0-0.2) * 1=0.8 \\
\text { CF-G18,G19 } & =0.32+0.4 *(1-0.32)=0.592 \\
\text { CF-G18,G19,G20 } & =0.8+0.592 *(1-0.8)=0.9184
\end{array}
$$

Kesimpulan: $0.9184 * 100 \%=91 \%$

Jadi Tanaman Bapak Guci Harianto terserang Defisiensi Nutrisi Zat Besi (Fe) dengan tingkat kepercayaan $91 \%$.

\subsection{Hasil}

Berdasarkan hasil pengolahan dari 4 contoh data dengan memanfaatkan metode Certainty Factor, maka didapatkan hasil yang disajikan pada Tabel 4.

\begin{tabular}{llll}
\multicolumn{3}{c}{ Tabel 4.Tabel Rule } \\
\hline Nama & Kode & Jenis Defisiensi & Hasil \\
\hline Guci Harianto & D07 & Zat Besi (Fe) & $91 \%$ \\
Khairil Anwar & D01 & Nitrogen (N) & $57 \%$ \\
Desrianto & D05 & Magnesium (Mg) & $91 \%$ \\
Alendra & D07 & Zat Besi (Fe) & $83 \%$ \\
\hline
\end{tabular}

Hasil dari Sistem Pakar dapat dilihat dengan menggunakan software yang telah dibangun menggunakan bahasa pemrograman PHP dan database MySQL. Berikut tampilan sistem pakar defisiensi nutrisi tanaman hidroponik.

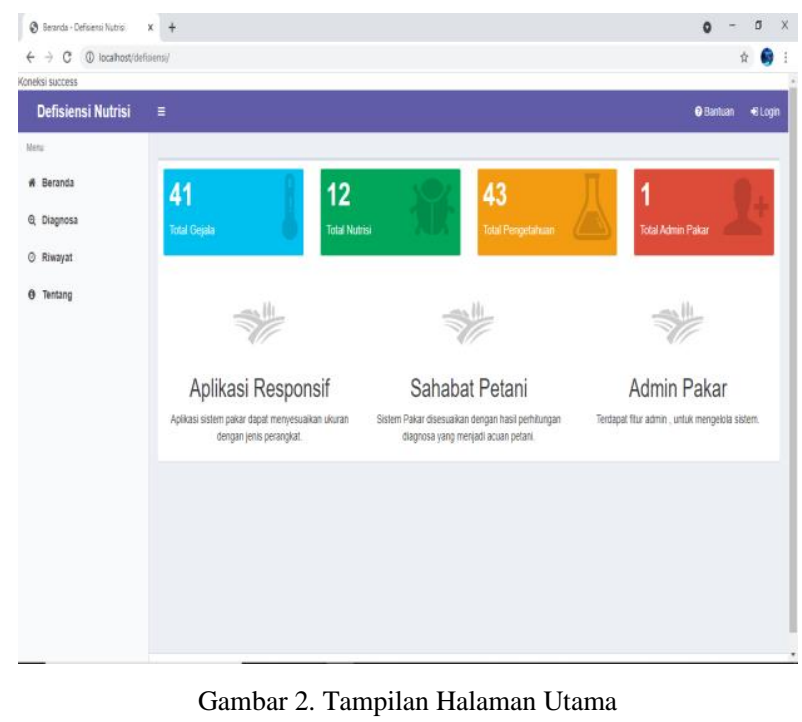

Gambar 2 menampilkan halaman utama aplikasi web browser Google Chrome untuk mengoperasikan program Sistem Pakar Defisiensi Nutrisi Tanaman Hidroponik.

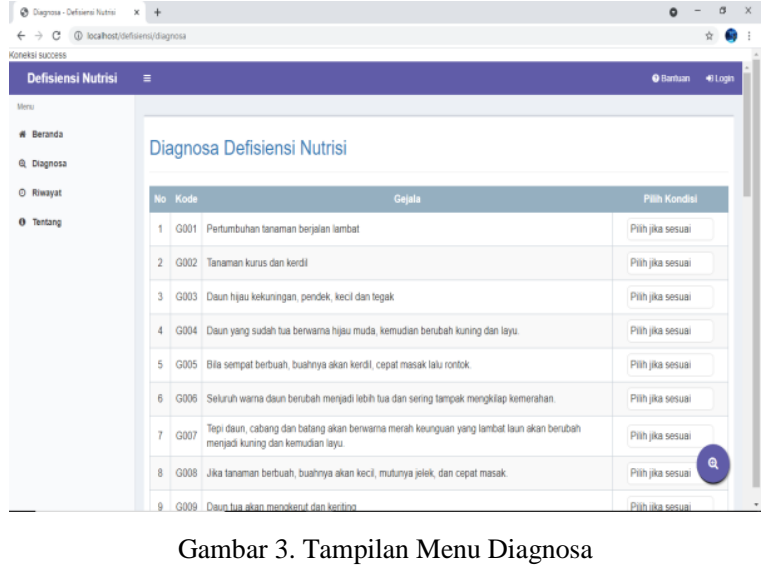

Gambar 3 memperlihatkan gejala-gejala defisiensi nutria tanaman hidroponik yang akan dipilih user. Terdapat 41 gejala defisiensi nutrisi tanaman hidroponik yang ada dalam aplikasi Sistem Pakar Defisiensi Nutrisi Tanaman Hidroponik.

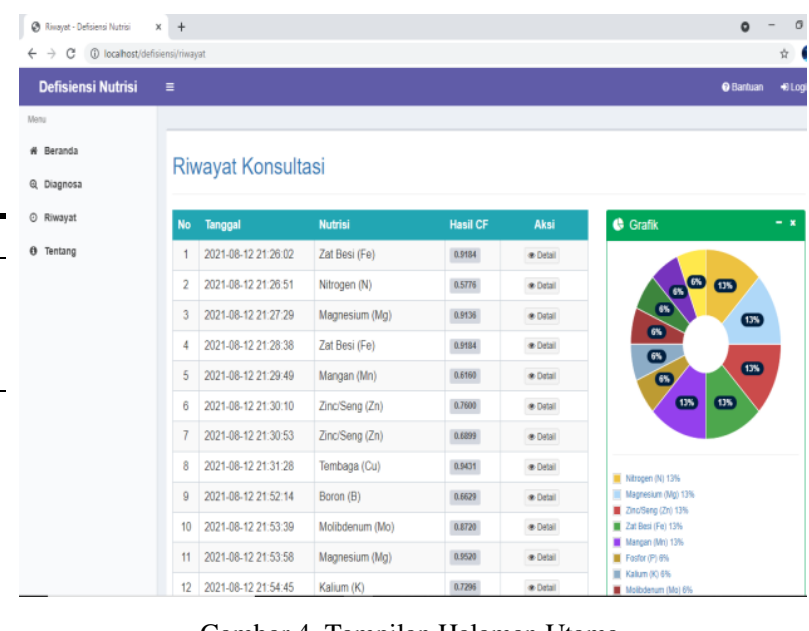

Gambar 4. Tampilan Halaman Utama

Gambar 4 memperlihatkan hasil konsultasi defisiensi nutrisi yang menunjukkan hasil analisis dari Sistem Pakar Defisiensi Nutrisi, dan jika pilih detail maka akan menampilkan hasil diagnosa secara detail.

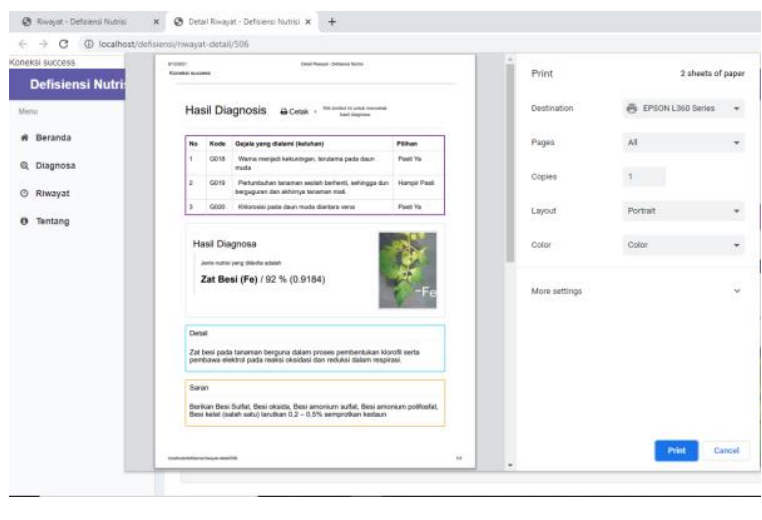

Gambar 5. Tampilan Halaman Utama

Gambar 5 memperlihatkan tampilan cetak hasil diagnosa Sistem Pakar Defisiensi Nutrisi Tanaman Hidroponik. 
Hasil rekap pengujian seluruh data dengan memanfaatkan metode Certainty Factor, maka didapatkan hasil yang disajikan pada Tabel 5.

Tabel 5. Tabel Hasil Rekap

\begin{tabular}{llll}
\hline Nama & Jenis Defisiensi & Hasil & Ket \\
\hline Guci Harianto & BESI & 92 & Valid \\
Khairil Anwar & NITROGEN & 58 & Valid \\
Desrianto & MAGNESIUM & 91 & Valid \\
Alendra & BESI & 84 & Valid \\
Willy Yulihardi & MAGAN & 62 & Valid \\
Riza Suryati & SENG & 76 & Valid \\
Darul Husni & SENG & 69 & Valid \\
Oskandar & - & 0 & Unvalid \\
Jeni Atmansyah & BARON & 66 & Valid \\
Hendrianto & MOLIBDENUM & 87 & Valid \\
Ferizal & MAGNESIUM & 95 & Valid \\
Aidil Fitri & KALIUM & 73 & Valid \\
Rahmad Rizki & PHOSFOR & 93 & Valid \\
Sahroni Yandri & NITROGEN & 54 & Valid \\
Hermaidinur & SULFUR & 84 & Valid \\
Delki Mendra & MANGAN & 84 & Valid \\
\hline
\end{tabular}

Berdasarkan pengujian akurasi pada Tabel 6 maka didapatkan nilai keakuratan Sistem Pakar Defisiensi Nutrisi Tanaman sebesar 94\% dengan metode Certainty Factor. Berdasarkan hasil akurasi tersebut maka Sistem Pakar ini sudah dapat digunakan untuk menganalisis Defisiensi Nutrisi Tanaman Hidroponik Menggunakan Metode Certainty Factor.

\section{Kesimpulan}

Penelitian ini dapat mengidentifikasi defisiensi nutrisi tanaman hidroponik dan menghasilkan nilai kepastian terhadap jenis defisiensi nutrisi Sehingga penelitian ini dapat menjadi rujukan dalam mengidentifikasi defisiensi nutrisi tanaman hidroponik serta memberikan pengetahuan kepada petani tentang penanganan defisiensi nutrisi tanaman hidroponik.

\section{Daftar Rujukan}

[1] Yigitcanlar, T., \& Cugurullo, F. (2020). The Sustainability of Artificial Intelligence: An Urbanistic Viewpoint from the Lens of Smart and Sustainable Cities. Sustainability, 12(20), 8548. doi: $10.3390 / \mathrm{su} 12208548$

[2] Pakpahan, A., Sagala, J. R., Yesputra, R., Lubis, A., Saputra, H., Husain, \& Sihotang, H. T. (2019). Implementation of Certainty Factor Method for Diagnoses of Photocopy Machine Damage. Journal of Physics: Conference Series, 1255, 012059. doi:10.1088/1742-6596/1255/1/012059

[3] Zhao, X. \& Chen, W. (2019). GIS-Based Evaluation of Landslide Susceptibility Models Using Certainty Factors and Functional Trees-Based Ensemble Techniques. Applied Sciences, 10(1), 16. doi:10.3390/app10010016

[4] Saputri, A. E., Sevani, N., Saputra, F., \& Sali, R. K. (2020). Using Certainty Factor Method to Handle Uncertain Condition in Hepatitis Diagnosis. ComTech: Computer, Mathematics and Engineering Applications, 11(1), 1-10. doi:10.21512/comtech.v11i1.5903

[5] Alim, S., Lestari, P. P., \& Rusliyawati, R. (2020). Sistem Pakar Diagnosa Penyakit Tanaman Kakao Menggunakan Metode Certainty Factor pada Kelompok Tani PT Olam Indonesia (Cocoa) Cabang Lampung. Jurnal Data Mining Dan Sistem Informasi, 1(1), 26. doi:10.33365/jdmsi.v1i1.798

[6] Rosi, M. F., \& Prakoso, B. H. (2020). Sistem Pakar Diagnosa Penyakit Tanaman Bawang Merah Menggunakan Metode Certainty Factor. BIOS: Jurnal Teknologi Informasi Dan Rekayasa Komputer, 1(1), 20-27. doi:10.37148/bios.v1i1.5

[7] Dholwani, S.J., Marvadi, S.G., Patel, V.P., \& Desai, V.P. (2018). Nutrients Required For Hydroponic System. International Journal for Research Trends and Innovation, 3(4), 195-199.

[8] Saleem, H., Khan, A.R., \& Jilani, T.A. (2020). Expert System for Diagnosing Mobile and Immobile Nutrients Deficiency of Plants. International Journal of Academic Information Systems Research (IJAISR), 4(8), 10-15.

9] Novaliendrya, D. \& dkk. (2020). Development of an Expert System Application to Detect Vitamin Deficiencies in the Human Body. Revista Argentina de Clínica Psicológica, 29(5), 956-965. doi: 10.24205/03276716.2020.1092

[10] Nath, P. (2018). An Expert System for Detection of Nutrient Deficiency Diseases of rice plant (With special reference to BTAD, Assam). International Journal of Creative Research Thoughts (IJCRT), 6(1), 190-202. 
